\title{
UTILISING PRA TO DEVELOP A POSTGRADUATE QUALIFICATION IN VISUAL IMPAIRMENT STUDIES
}

\section{Manis}

Free State Department of Basic Education

Kroonstad, South Africa

e-mail: pm.thabe@gmail.com / https://orcid.org/0000-0002-4172-6209

\section{R. Ferreira*}

e-mail: ronel.ferreira@up.ac.za / https://orcid.org/0000-0003-2518-7839

\author{
M. M. Sefotho \\ Department of Educational Psychology \\ University of Johannesburg \\ Johannesburg, South Africa \\ e-mail: maximus.sefotho@uj.ac.za / https://orcid.org/0000-0003-0704-1983
}

\section{R. M. Mampane*}

e-mail: ruth.mampane@up.ac.za / https://orcid.org/0000-0002-9853-2077

*Department of Educational Psychology

University of Pretoria

Pretoria, South Africa.

\section{ABSTRACT}

This article reports on the study that focused on the utilisation of a Participatory Reflection and Action (PRA) methodology in order to develop a postgraduate qualification in visual impairment studies. The broader project aims to create ways in which learners with visual impairment can be included in South African schools. In lieu of this, it has therefore come to our attention that teachers of these learners in full service schools (FSS) and special needs schools may require appropriate education and training so as to effectively work with learners with visual impairment. For our exploration, we followed a case study design and utilised PRA approach as the main data generation source in the five provinces that were involved in the study. The sample involved 255 teachers in full service and special needs schools and 50 expert stakeholders in the field of visual impairment. To most teachers, being involved in PRA-based workshops was somewhat new, thus, our study found that teachers have varying views in terms of them (teachers) being part of PRAbased workshops. Although most of them commend the process of these workshops, others feel that there could be an opportunity for improvement.

Keywords: Advanced Diploma in Visual Impairment studies, expert stakeholders, full service schools, Inclusive education, Participatory Reflection and Action (PRA), postgraduate 
qualification, programme development, special needs school, visual impairment.

\section{INTRODUCTION}

Participatory Reflection and Action perceives social groups as custodians of indigenous knowledge and local resources that can be distributed among the local people (Kapoor and Jordan 2009). As a participatory methodology, PRA perceives participants as research partners and promotes power equalisation between all those involved in the research. As such, it demotes the idea that researchers should be the ones in the forefront, telling participants what to do and how. As much as PRA is a product of many research approaches, researchers using this methodology rather allow themselves to learn from the participants. Researchers enter the field with the knowledge that participants are the experts of their own circumstances and they (participants) know better what will work for them in actively bringing about change. In this way, participants are motivated to become change agents as they learn from each other and researchers also learn from them. In PRA, the main role of the researcher is to facilitate the process of change.

As Chilisa $(2012,237)$ refers to it as a "people-centred methodology", PRA enables partnership and collaboration as it is applied in various contexts. Participants who are involved in such a methodology are encouraged to work together to combat the challenges they are going through and bring about solutions that can sustainably resolve these challenges. PRA promotes collaborations between different stakeholders in similar or even different fields of study (FalsBorda 1991). These collaborations can extend to scholars/academics, government departments officials and private organisations among others. The aim of collaborations in PRA is for the sharing of information and also ensuring that adverse situations are somehow resolved. As much as PRA is mostly applied in rural and/or challenged areas, it is meant to bring people together in such a way that they can together recognise their assets and resources.

The purpose of relying on PRA methodology for our study was due to the fact that we wanted to get teachers and stakeholders together, to representatively participate in the development of a postgraduate qualification in visual impairment studies. The problem that was realised and attempted to be addressed was that teachers may not have adequate training to work with leaners with visual impairment, thus the sampled participants were perceived to assist us with the kind of data required. Through the observation that there is no existing qualification in visual impairment in South African (which is another problem that this research seeks to address) and funding received from the European Union (EU) and the Department of Higher Education and Training (DHET), we deemed it necessary that teachers should have a disability specific qualification accompanied by knowledge and skills that will assist them in 
teaching and supporting learners with visual impairment.

In South Africa, for a qualification to be approved there is a process that needs to be followed. This includes getting the qualification approved and registered by different professional authorities (Janse van Rensburg 2005). Issues of entry requirements, demand and type of knowledge and skills the qualification will provide need to be considered when developing a qualification. The South African Qualification Authority (SAQA) stipulates that a qualification cannot be offered without meeting the required criteria and being approved by National Qualification Framework (NQF) (SAQA 2013). The qualification developed during this study has therefore met the requirement and it has been deemed significant to address the needs and challenges of teachers working with learners with visual impairment. To get to where we are at the moment, we initially conducted research with teachers in exploring their needs, expectations and competencies in terms of implementing inclusive education policy (White Paper 6) in teaching and supporting learners with visual impairment. The manner in which they understand inclusive education, its implications for them and their level of readiness were also explored. In this article we report on the utilisation of PRA with teacher-participants in developing a postgraduate qualification in visual impairment studies.

\section{FUNDAMENTAL TENETS OF PRA}

Grenier (1998) stipulates the basic tenets of PRA as being the ability of PRA to respond to participants' behaviours and its sensitivity to culture. Secondly, PRA allows for the use of multiple data generation and documentation sources. This is beneficial to researchers as flexibility may be exercised. When engaging with participants using PRA (or any type of research method) it is imperative to consider that not all participants are literate and/or can read and write, thus the use of multiple data sources, particularly audio-visual sources will accommodate disadvantaged participants (Grenier 1998). In the third instance, PRA is known for its utilisation in qualitative and quantitative approaches, giving researchers of both approaches an opportunity to engage with participants collaboratively (Grenier 1998).

When engaging with participants during PRA, it is important for researchers to be able to submerse themselves with the participants' culture and allow themselves to be taught by participants (Gibson 2002). Therefore, the daily experiences of participants need to be taken into account. For participants to be able to freely engage with researchers, as they (participants) may view them as outsiders, there has to be reciprocal trust. Participants need to be reassured that researchers will do them no harm and that they will be ethically protected throughout the research process. PRA methodology is a reminder to researchers that participants know their situations best and there should be no imposing of knowledge to the participants. 
The process of PRA leads to participants' being able to identify their strengths and resources. It is the aim of PRA for participants to have positive change as they could be targeted by researchers as needing that. Thus, throughout the PRA process, participants are empowered to work together to identify and capitalise on what is in the community in order to resolve the challenging situation they may be facing (Chambers 1994). This process however requires that participants be involved from the beginning and actually be willing to change or impact change by using they have in their community, essentially participants need take ownership of the change process (Chambers 2008). This in turn facilitates participants' independence and the ability to continue promoting change even after researchers have left.

Furthermore, PRA advocates that the research needs to take place in the participants' context (Cheatham-Rojas and Shen 2008). Although behaviour modification may occur, this is important because participants are believed to be comfortable in the natural setting than when taken aware to be "researched" at a different location. The willingness, commitment and resilience of participants need to be witnessed in their setting so that there can be surety that participants will be able to sustain the supportive measures planned with them (Cheatham-Rojas and Shen 2008). There is a need by PRA that participants need to be able to "do it" themselves (Chambers 1994, 1254). This then mean that participants' willingness and involvement are key.

\section{THE CHOICE TO RELY ON PRA}

PRA has proved itself suitable for our study as it had the principles that we applied in the field. As we involve ourselves in research that makes a positive impact in participants' challenging situations and lives, we believe that participants become research partners as opposed to being passive receivers of support and assistance from researchers or outsiders (Cheatham-Rojas and Shen 2008). As they partner with researchers, participants are able to take ownership of the processes that affect them and take place in order to support their adverse situation. It has become important for us to take note of the fact that we do not impose our opinions and ideas on to participants as they are the experts of their context (Cheatham-Rojas and Shen 2008). Thus our role became that of facilitating PRA-based workshops as participants were involved in the analysis of their needs, expectations and strengths.

Furthermore, as researchers and academics, we believe in the essence of information sharing. As we interact with participants and they interact with one another, there is sharing of information that takes place. Not only information but knowledge is shared among participants as they sat and discussed in the groups (Chambers 1994). Not only do they share among themselves, participants share their knowledge with researchers as they engage in presentations to the larger group (Chambers 1994). And we as researchers we also share the knowledge we 
have received with one another and with other researchers and academics (Chambers 1994).

According to Chambers (1994) PRA permits the poor to be expressive and engage in the analysis of their circumstances and lives' realities and also be much involved in the planning, monitoring and evaluating the suitable actions towards their solutions. In this manner, as researchers, we allowed participants to be themselves and freely express their ideas and perceptions regarding the topic that was under study. As much as the participants in this study were not necessary poor in the essence of the word, they were teachers who needed to recognise their potential and act in a way that will enable them to be effective to learners with visual impairment. Through their confidence in the presentation of their ideas, participants proved that they are willing to face and challenge the situation at hand.

We further chose PRA because of its flexibility, ability to save time and also its cost effectiveness (Chambers 1994). Although PRA allows for the use of multiple sources of data, formulating groups for data generation saves time and costs and allows both researchers and participants to be flexible in terms of the direction of the process. These elements allowed us to equalise power between us and participants and empower them to seek solutions for engaging, teaching and supporting learners with visual impairment in an inclusive setting. As such, we respected and celebrated differences as PRA requires (Chambers 1994). This was however achieved through the building of rapport with participants and recognising our differences and embracing them instead of allowing them to disrupt us. Following these, collaboration was then established and a collective means of reaching agreements (through communication) with participants was reached (Chambers 1994).

\section{THE EXPERIENCES OF LEARNERS WITH VISUAL IMPAIRMENT}

Learners with visual impairment may experience challenges within the school context. In this section we discuss the needs and challenges experienced by learners with visual impairment in the school context, this discussion will focus on their school-related and psychosocial needs and challenges.

\section{School-related challenges and needs}

The ability to see is valued as one of the five basic senses that human beings use for learning and communication. Limited or absence of vision can have detrimental effects on one, especially on a learner's learning and development (Kapur 2018). Delays in the development of a range of visually-related skills can, for example, compel learners to depend on their remaining senses, namely listening, touching, tasting and smelling when acquiring new knowledge and skills (NICHCY 2012). As vision allows one to interact with the environment, 
learners with visual impairment may be affected more strongly than others by environmental factors, such as light and fatigue when attempting to interact with the environment and others (Waterfield and West 2008).

However, learners with visual impairment are occasionally still expected to develop and learn like their sighted peers (Kapur 2018). As can be expected, this is difficult, and requires specific adaptations. For their own benefit, learners with visual impairment may, for example, need to learn how to move around in their environment safely; if not yet blind, by utilising their limited vision. In addition, some learners may require assistive devices or may have to rely on Braille for reading and writing (American Foundation for the Blind 2011). Due to a lack of sufficient specialised institutions for learning and adequate human resources that can support learners with visual impairment, it has become increasingly important for such learners to be admitted to and supported in inclusive or full service schools in South Africa.

As indicated, learners with visual impairment display specific school-related needs. As they experience difficulty to observe and note visual cues provided in the environment, it is important for these learners to be trained on how to use their other senses effectively (Sacks and Silberman 2000). Even though visual impairment does hinder a learner's ability to manipulate stimuli that depend on vision, abstract reasoning that relies on tactile and auditory concepts can be developed (Mosca 2015). If born visually impaired or if visual impairment develops at an early age, a learner's language and cognitive development may also be affected (Willings 2017), necessitating the need for additional stimulation and support.

Learners with visual impairment are furthermore often challenged by a limited attention span and may experience problems with memory (Fazzi, Galli, and Micheletti 2012). These learners may struggle with communication in terms of the recognition of items belonging to similar semantics. To this end, they may make comments that seem irrelevant in the specific context (Mosca 2015; Tadić, Pring, and Dale 2010). In addition, as learners with visual impairment are unable to view pictures and diagrams when being taught subject content, these aspects need to be taught and communicated in ways that make sense to them, and encourage their participation in the learning process (Penda, Ndhlovu, and Kasonde-Ng'andu 2015).

Therefore, learners with visual impairment need to be accommodated in more than one way in the school context. They need to have access to the curriculum as well as the learning material in such a way that they may learn and develop (Kapur 2018). For learners with visual impairment to be able to learn optimally, most teaching has to take in verbal format and possibly include tactile components, where learners use their other senses to participate in educational activities (Carney et al. 2003). To this end, the curriculum needs to be adapted in ways that may benefit these learners, and teachers need to be experienced in verbally providing lessons and 
assessment tasks, include Braille material for learners to participate in learning, and use repetition when explaining new content so that learners with visual impairment can understand and form part of the instruction and learning process (Johnson-Jones 2017). Additionally, for these learners to be able to thrive scholastically, they need to be accommodated in terms of classroom seating arrangements with sufficient space between chairs and desks, with partially sighted learners seated in front or in a position that allows them to best see the teacher and the provision of material such as Braille, large font print and/or audio tapes (Mastropieri and Scruggs 2010; Tadić, Pring, and Dale 2010).

As indicated, learners with visual impairment can be made aware of what is taking place in class through verbalisation and by involving the remaining senses and also their skills for spatial perception (Andreou and McCall 2010; Bradley-Johnson and Morgan 2002). Since these learners, especially those who are totally blind, cannot easily participate in learning that involves normal textbooks, Braille books as well as other audio material and related assistive devices are important (Johnson-Jones 2017). In many cases teachers are not sufficiently equipped to work with learners with visual impairment, making the use of assistive devices, curriculum differentiation and the adaptation of teaching methods difficult (Silberman, Bruce, and Nelson 2004). Some strategies that teachers may rely on include the implementation of hands-on learning, keeping rules similar for everyone, teaching from the concrete to abstract level, talking out loud when writing on the writing board and providing copies of what is being presented to the partially sighted even if they read through magnifying glasses, being specific/descriptive when communicating with learners, and explaining changes or transitions before they occur (Negash 2017). In this regard, it is important for learners with visual impairment to be well prepared for any form of transition, either moving from grade to grade or from school to tertiary level (Carney et al. 2003).

In terms of physical resources, the infrastructure and school buildings need to suit the needs of learners with disabilities, including those with visual impairment (Department of Education 2005b). In class, teachers typically provide support on a practical level by rearranging classroom furniture to allow learners with visual impairment to move around freely, seating learners with visual impairment in front or in a position where they can see better, or by adjusting the classroom lighting (Lamichhane 2017). Some other accommodations involve teachers verbally teaching and assessing learners with visual impairment rather than giving them written work, thereby adapting their teaching and assessment practices (Kamal, 2017; Lamichhane, 2017). Teachers can furthermore create special material, such as counters in Braille to accommodate learners with visual impairment and make the curriculum accessible to them. For practical support, learners require suitable Learning and Teaching Support Material 
(LTSM) and assistive devices that may enhance their learning and support their participation in assessment tasks. In addition, these learners require human resources in the form of skilled teachers and qualified support personnel, such as teacher assistants, school nurses, occupational therapists, Braille instructors, as well as orientation and mobility instructors to facilitate their learning and acquisition of skills in the school environment (Brown and Beamish 2012; Department of Basic Education 2001).

\section{Psychosocial challenges and needs}

Visual impairment may hinder the development of a positive self-concept, which in turn can result in social relationship problems and/or poor scholastic performance (Augestad 2017). Learners' self-concept typically comprises physical, moral, personal, family, social and academic aspects, and the related views of a person of the self (Datta and Talukdar 2016). It is important that learners with visual impairment experience a sense of belonging, accompanied by healthy relationships with their peers that can promote their confidence, wellbeing and safety (Ministry of Education 2006). To this end, it is important to make learners aware of their strengths, talents, interests and learning styles, and encourage them to have dreams and aspirations as well as the courage to realise these (Ministry of Education 2006).

Another important developmental aspect for any learner is emotional development, coupled with emotional intelligence (Kumar and Signh 2013). As in the case of learners who can see, it is important for learners with visual impairment to learn how to deal with their emotions when in an environment that is not necessarily supportive in terms of their disability (Kumar and Signh 2013). These learners often face stigma and possibly even humiliation by their peers who may not understand them. As such, it is important for them to know how to respond in such cases in a suitable way (Kass 2012; Ueda 2018). At times, these learners may feel embarrassed, especially when they reach their adolescent years and realise that they are not able to demonstrate socially expected norms optimally (Schinazi 2007). They may feel uncomfortable and self-conscious, and as a result withdraw socially or even become defiant (Schinazi 2007). In response, teachers and parents need to support these learners by, for example, teaching them how to deal with negative emotions by becoming aware of their feelings and what aggravates them, monitoring negative emotions and responding in suitable ways when being aggravated (Kass 2012).

A study by Fitts and Warren (2003) indicates that learners with visual impairment generally compare themselves to their sighted peers and then realise that they do not match the social and academic skills and abilities of others (Datta and Talukdar 2016). As a result, learners with visual impairment often have a low self-concept, as indicated in the previous paragraph. 
In addition, they need to be taught appropriate and acceptable etiquette, including suitable interpersonal communication in to be able to relate to their peers. They may also face the risk of being mocked or bullied by their sighted peers, with their views not necessarily being respected in scholastic and/or social settings (Brydges and Mkandawire 2016).

As a result, learners with visual impairment may display limited faith in their sighted peers when requiring assistance (Mosca 2015). At the same time, sighted learners may similarly not be reliant and/or interested to assist learners with visual impairment at all times, whether in the classroom or outside the school setting (Brydges and Mkandawire 2016). Despite the possibility of stigma and stereotyping of learners with visual impairment, it is necessary that their human rights are respected and protected by both teachers and other learners, who need to be conscious of and respect diversity.

As learners with visual impairment often feel that other learners or adults do not understand them, they may withdraw socially, resulting in their having fewer friends than what is optimal (George and Duquette 2006). Such withdrawal can result in additional challenges related to the underdevelopment of social skills due to the visually impaired having limited visual contact with the people and surroundings around them, and not being able to imitate visual cues, or to develop interpersonal skills (Khalim, Norshidah, and Zalizan 2011; Landsberg, Kruger, and Nel 2015; Tolman, Hill, Kleinschmidt, and Gregg 2005). Furthermore, if not trained to become independent, learners with visual impairment may develop learned helplessness and then tend to overly rely on others, such as their parents or caregivers (George and Duquette 2006). However, all these experiences seem to differ between male and female learners.

In this regard, it is important for learners with visual impairment to gain knowledge of conventional social cues that may assist them in navigating their way in society and earning respect in the school setting among their peers (Datta and Talukdar 2016). Although some learners with visual impairment may not be able to experience cues and responses from their environment visually, it remains important for them to learn how to behave in a socially acceptable manner (Bailey 2009). To this end, teachers are required to promote acceptable behaviour among learners with visual impairment by teaching them how to behave in public and informing them of acceptable social behaviour. Once again, this task is not solely dependent on the teacher, as the learner needs to be willing to learn and practise acceptable behaviour. In addition, parents need to ensure that the newly acquired behaviour is emphasised and reinforced at home (George and Duquette 2006; Kass 2012). Finally, learners can be paired with peers who may demonstrate and explain acceptable behaviour to the learner with visual impairment to learn from others (Sacks and Wolffe 2006). 
It remains important to guard against learned helplessness and the possibility of dependency when pairing learners, as the learner with visual impairment may view this as an opportunity to receive help in all circumstances (Khalim et al. 2011). If the mentioned strategies are not successful, learners can be referred for professional support to acquire socially acceptable behaviour and mannerisms (Sacks and Wolffe 2006). Throughout, it remains important for learners with visual impairment to acquire self-care skills, such as daily living skills to take care of themselves in terms of feeding, dressing, and bathing, to mention but a few required skills (Ministry of Education 2006).

Finally, learners with visual impairment may experience difficulty in accepting their disability. They may, for example, experience their disability as unfair and in this way prevent themselves from fully embracing life (Ueda 2018). Furthermore, learners with visual impairment may be easily frustrated, particularly when they fail scholastically or in mastering important skills. If learners struggle with the skill of regulating their emotions or dealing with their frustrations, they may require professional support to accept their disability, identify negative feelings and develop coping mechanisms to deal with and express these in a suitable way (Kumar and Signh 2013).

\section{SCHOOL PROVISION FOR LEARNERS WITH VISUAL IMPAIRMENT IN SOUTH AFRICA}

The provision of equal educational opportunities in South Africa has been problematic for many years (Habulezi and Phasha 2012; Terzi 2005). Apart from limited access to education due to ability and racial differences during the apartheid years, support and schooling for learners with disabilities were generally neglected in the past (Berry 2008). Many learners have been kept out of school because they do not meet certain scholastic standards or are differently abled (Habulezi and Phasha 2012). Although amends have since been made to accept all learners in schools regardless of their (dis)ability, some schools remain reluctant to follow this route (Department of Education 2005a). This reluctance may be ascribed to a number of reasons, such as a shortage of specialised or trained teachers and other staff members, or the absence of specialised facilities.

In South Africa, different types of government funded schools exist, which differ in terms of the levels of support provided to learners who may have special needs. The first category of schools is mainstream schools - also referred to as public ordinary schools. These schools generally provide education for developing learners, with the level of individual support being low to moderate, focusing on activities such as differentiation during lessons to cater for different learning styles (Department of Basic Education 2001; Ferguson 2014). However, 
these schools cannot exclude learners with special needs who want to enrol. Next, full service schools, these are specifically earmarked mainstream schools also known as inclusive schools, with the aim to accommodate all learners in an inclusive setting (Department of Basic Education 2001). The level of support in these schools, ranges from moderate to high as they are supposedly equipped with specialised support resources and staff, such as remedial and special needs teachers. The physical infrastructure at these schools is also expected to be suitable for learners with special needs (Department of Basic Education 2010). Finally, special needs schools, often referred to as resource centres, generally admit and accommodate learners with intellectual and sensory disabilities (KwaZulu Natal Department of Education (KZNDoE) and MIET Africa 2010). The level of specialised support provided at these schools is high as specialists, such as psychologists and other therapists are available at the school. As a result, specialised support is provided on-site. Full service schools can also request assistance from these schools (KZNDoE and MIET Africa 2010).

According to the EMIS report (Department of Basic Education, 2016), 29749 public and independent schools existed in South Africa in 2016, with 25574 being mainstream schools and 4175 other educational organisations, such as Early Childhood Development centres (ECD) and special needs schools. As such, public mainstream schools accounted for 92 per cent, independent schools for 4,4 per cent, ECD centres for 1,9 per cent and special needs schools for 0,9 per cent (Department of Basic Education 2016), highlighting the shortage of special needs schools in South Africa. More specifically, in South Africa a mere 715 designated full service schools and 464 special needs schools currently exist, of which only 22 are for the visually impaired across all nine provinces of the country (Department of Basic Education 2016).

The above-mentioned total number of schools in the country are served by 440151 teachers (Department of Basic Education 2016). Some of these teachers have been exposed to an extent to the implementation of inclusive education policy, yet others have not. In addition to the need for specific training on differentiation of the curriculum, many teachers have not yet received any general training on working with learners with visual impairment or for that matter, other disabilities (Busemeyer and Vossiek 2015).

\section{SCHOOL-BASED SUPPORT FOR LEARNERS WITH VISUAL IMPAIRMENT}

Learners with visual impairment require ongoing support on multiple levels in the classroom. In addition to support on a scholastic and practical level, for example large print and Braille documents, these learners need to be supported on social and emotional levels (Lane et al. 2010) More specifically, learners with visual impairment may feel lonely, struggle to be accepted, 
need to compete with sighted learners, or feel pressurised by their school work and related demands (Verdier 2016). As such, constructive feedback from people in the school environment - both peers and teachers - positive attitudes and easy access to the physical environment are important to attend to in the schools and classrooms where learners with visual impairment are accommodated (Roe 2008).

Professionals such as occupational therapists, speech therapists and optometrists can make a positive contribution to the implementation of an inclusive education policy. As most of these professionals in South Africa operate on a private practice basis or in hospital settings, these services may not be easily accessible to all learners and their families due to long distances to places offering the services, or such services being too expensive to afford by a large percentage of the South African population, specifically those without medical aid. Some individual needs of learners can be met through consultation between parents and these professionals, or when professionals work closely with the teachers of learners with visual impairment, providing them with strategies on how to support the learners (Department of Basic Education 2010).

Under-resourcing inevitably prevents schools from optimally accommodating learners with disabilities. In this regard, the need for specialised classroom technology for learners with disabilities remains prevalent in South African schools. According to Bayram et al. (2015) who conducted a study on inclusion in Mathematics classrooms with high school learners with visual impairment, these learners often require access to programmes such as Job Action with Speech (JAWS) to be able to use computers. Learners who participated in the study noted that they themselves mostly had to buy their writing materials and other assistive devices, implying a financial burden for them and their families (Bayram et al. 2015).

Currently, teachers at special needs schools often focus on teaching learners Braille and conduct summative assessment by using Braille. This holds the advantage of learners being able to use Braille in support of their learning (Kamal 2017). Other than Braille, some assistive devices are used in selected privileged special needs schools, yet not in all schools, thereby exposing only some learners to these devices (Lamichhane 2017), which include apex, computers with large screens, and embossers and Braille printers, among other resources (UNESCO 2001).

In class, teachers typically provide support on a practical level by rearranging classroom furniture to allow learners with visual impairment to move around freely, seating learners with visual impairment in front or in a position where they can see better, or by adjusting the classroom lighting (Lamichhane 2017). Some other accommodations involve teachers verbally teaching and assessing learners with visual impairment rather than giving them written work, thereby adapting their teaching and assessment practices (Kamal 2017; Lamichhane 2017). 
Teachers can furthermore create special material, such as counters in Braille to accommodate learners with visual impairment and make the curriculum accessible to them.

Outside the classroom setting, some schools in South Africa have flattened the school grounds and/or built ramps to prevent learners with visual impairment from falling or struggling to use staircases (Kamal 2017). Significant signage and warning signs are typically added in colour, for example yellow that suits learners with low vision. Common areas such as bathrooms, transport stations, libraries and computer centres are usually adapted in a way that can support learners with visual impairment (Niyisabwa 2016; UNESCO 2004). For learners who conduct experiments in school laboratories, an interfacing of equipment with large computer screens or verbalising text may be used (Waterfield and West 2008). All such adaptations can be supported when an on-site occupational therapist is available to orientate learners and intervene in relevant ways.

As already indicated, the teaching and supporting of learners with visual impairment requires a holistic team approach (Johnson-Jones 2017). More specifically, the teacher and school community cannot efficiently teach and support these learners on their own, and require the support of others. Therefore, parents, caregivers and other community stakeholders such as health departments, social workers and child protection units need to be involved, to mention but a few (Department of Basic Education and MIET Africa 2010). The involvement of such role players can ensure that learners' right to quality education can be met and that they are supported in a manner that may enable them to participate optimally in their own learning activities and to be accepted in the school environment (Department of Education 2007). In the case of the parents, they can offer therapeutic activities at home and provide continued support to learners with visual impairment (Department of Education 2007).

In the South African context, teams that deal with learner support and special needs education are compiled in the school system. These teams are referred to as School-based Support Teams (SBST) and their major function is to identify, assess, provide support or refer learners with special needs to external service providers (Department of Basic Education 2001; Masango 2013). These teams are also meant to support teachers who work with learners with special needs or experience challenges in doing so. In cases where a learner requires special support, the SBST at the school, in collaboration with the referring teacher, draws up an individual support plan (ISP), stipulating relevant support strategies that may assist the learner in accessing the curriculum and optimally participating in any learning activities (Department of Basic Education 2015a). Ad hoc members, such as remedial teachers from other schools, social workers and retired teachers can be invited for contributions on how to support learners with specific special needs (Masango 2013). 
As SBSTs generally provide support to both teachers and learners in the school context, only the cases that cannot be resolved and efficiently supported through this structure are referred to a District-based Support Team (DBST) that will then provide support to the learner through the SBST and monitor the progress (Department of Education 2005b). The DBST consists of specialists such as psychologists, occupational and speech therapists, learning support advisors, subject advisors, as well as officials from procurement and finance sectors, to mention but a few. These teams thus involve various sections and fields of potential support in the district, with relevant role players becoming involved according to the specific referral (Department of Education 2005b). After referral of a learner to the DBST, the learner is assessed by relevant specialists (psychologist, occupational therapist and/or speech therapist) depending on the referral. An intervention plan is then developed, indicating the responsible people for the implementation of the plan (Department of Basic Education 2001).

Such a support process is always carried out in collaboration with the referring teacher, the SBST coordinator, the learner's parents who need to provide their consent for the referral, assessment and intervention, and with members of the DBST. In cases where the intervention requires a subject advisor to guide the teacher on how to present a particular subject to the referred learner, the advisor also provides strategies on which skills to develop and on curriculum differentiation in support of learner performance (Department of Basic Education 2001; Ferguson 2014). As part of such a team, the responsibility of procurement and financial officials is to ensure that learners who require, for example, assistive devices are supplied with these. For this task, private suppliers of such devices or the Department of Health may also become involved. If a learner still does not progress as expected despite all such support efforts, referral is made to a relevant special needs school (Department of Education 2007).

\section{METHODOLOGY}

The study reported in this article forms part of a broader EU/DHET funded research project that focuses inclusion of learners with visual impairment in the South African context. The main objective of this project was for the University of Pretoria researchers to develop a postgraduate diploma in visual impairment studies that will serve the purpose of equipping teachers, prospective and practicing, to teach and support learners with visual impairment. The aim of the study was to find a way of supporting teachers through the development and offering of a postgraduate qualification to implement the inclusive education policy more effectively to address the needs of learners experiencing special educational needs, more specifically those who experience learning difficulties as a result of visual impairment. Due to the fact that many teachers in inclusive and specialised schools are inadequately trained to work with learners who 
experience learning difficulties (Berry 2008), the qualification that is developed as part of the EU/DHET project will focus on both practising and future teachers in terms of skills acquisition to teach, assess and support learners who face difficulties effectively. As part of the broader funded project, this study specifically focused on the process of developing the Advanced Diploma in Visual Impairment Studies by implementing PRA principles to access the knowledge and expertise of the participants. This qualification is rooted in White Paper 6 on special needs education (Department of Basic Education 2001) and will target current as well as future teachers. Effective implementation of the inclusive education policy by teachers implies the possibility of schools becoming better resources in themselves, not having to refer all learners who experience barriers to learning to specialised institutions. In attaining baseline data prior to developing the qualification, out of nine provinces in the country we facilitated PRA-based workshops across five provinces and two with stakeholders. These took place between November 2017 and April 2018. Our epistemological paradigm was interpretivism and we relied on a participatory approach (Carcary 2009).

\section{Overview of the broader EU/DHET-funded research project}

The broader EU/DHET-funded project commenced in November 2016 and involves five phases. In addition to the project focusing on the development of an Advanced Diploma, Open Educational Resource (OER) material is currently being developed and a Centre for Visual Impairment Studies is being established at the University of Pretoria.

The first phase of the project (2016) entailed the initial conceptualisation of an Advanced Diploma in Visual Impairment Studies by academic staff members involved in the project, and applying for related approval from the relevant institutional and external bodies. As the development of the final module content was based on research with teachers and stakeholders in the field, ethical clearance was obtained from the University of Pretoria and the relevant Departments of Education, as part of Phase 1 of the project.

The second phase of the project (2017 to 2018) involved data generation with teachers in both full service and special needs schools in five of the nine provinces of South Africa, as well as with expert stakeholders working in the field of visual impairment. During this phase, research was conducted on the needs, expectations and ideas of the participating teachers and stakeholders, which served as background for developing draft module outlines for the Advanced Diploma qualification (Phase 3, 2018). Next, member-checking was conducted with the initially involved teachers and stakeholders as Phase 4 of the project to confirm the proposed draft module content before commencing with module development.

During the fourth phase of the project (2018), the draft programme outline and proposed 
module content were presented to the participants, requesting their input to revise the proposed module content where needed, based on the feedback and input received. The fifth and final phase of the project that is currently underway entails final approval of the programme and modules on national level; development and finalisation of the modules as well as the associated OER learning material; implementation of the programme, and continued monitoring and evaluation for the purpose of quality assurance and revision when required.

\section{Research design and selection of case and participants}

We employed a multiple case study design and relied on participatory reflection and action (PRA) principles for our study (Gerring 2004). We therefore partnered with teachers from various schools and stakeholders as specialists in this field as we explored their perspectives with regards to inclusive education and visual impairment through the use of PRA-based workshops. Prior to starting the fieldwork, the assumption was that teachers in South Africa are informed about inclusive education policy and that the implementation of the policy will be beneficial to the learners they teach as the policy was released almost 19 years ago and teachers were expected to start with the implementation. This assumption then led researchers to expect an in-depth knowledge and understanding inclusive education, however, this assumption was incorrectly proven as fieldwork began. Although, teacher-participants were still regarded as specialists due to the fact that they have a first-hand experience in working with learners, whether presenting with disabilities or not, they know and understand their own needs and those of the learners clearer the research team. This then puts them as experts of the topic under investigation. Involved stakeholders are regarded as specialist as they originated from different organisations within the visual impairment community as illustrated in Table 2 . In this article we report the findings of the teachers' experiences and views on the utilisation of PRA, particularly them being involved in the process as research partners in the development of the qualification.

As a first step, the research team obtained a list of all schools in South Africa from the national Department of Basic Education, we identified 17 schools as cases, situated in five different provinces, namely the Eastern Cape (EC), Free State (FS), Gauteng (GP), KwaZuluNatal (KZN) and Limpopo province. A nationwide invitation was extended to the provincial Departments of Education, inviting participation of the identified schools, and requesting departmental permission to proceed with arrangements for site visits. The first three provinces that responded and granted permission to conduct research in the relevant schools were then visited for data generation while awaiting approval from the other two provinces. As stated, specific schools were purposefully selected from the various provinces. Three to four schools 
were then purposefully selected (Given 2008) in each of the provinces, two special needs schools and one or two full service schools that were supposedly implementing inclusive education policy or had been earmarked as inclusive schools. The teachers were selected in order to obtain their perspectives on their inclusion (or not) of learners with visual impairment in their respective school contexts, the needs of learners with visual impairment and how could they as teachers support these learners. Furthermore, teachers also reflected on their experiences of the PRA process and being part of developing a qualification. Table 1 captures the teacherparticipants. The following selection criteria applied in selecting the teacher-participants:

- Participants had to be teaching at full service or special needs schools, or worked in the field of visual impairment in South Africa.

- Participants in special needs schools had to be working with learners with visual impairment.

- Participants had to be knowledgeable about visual impairment and/or the needs experienced by people who work with learners with visual impairment.

- Participants had to be able to understand and communicate in English.

- $\quad$ Participants had to be willing to participate and provide informed consent.

- Participants had to be available to participate in a series of PRA workshop sessions at their respective schools, followed by a member-checking colloquium at a central venue a few months later.

Table 1: Summary of participating schools and teachers

\begin{tabular}{|l|c|c|c|c|}
\hline \multirow{2}{*}{ Province } & \multicolumn{2}{|c|}{ Full service schools } & \multicolumn{2}{c|}{ Special needs schools } \\
\cline { 2 - 5 } & $\begin{array}{c}\text { Number of } \\
\text { schools }\end{array}$ & $\begin{array}{c}\text { Number of } \\
\text { teachers }\end{array}$ & $\begin{array}{c}\text { Number of } \\
\text { schools }\end{array}$ & $\begin{array}{c}\text { Number of } \\
\text { teachers }\end{array}$ \\
\hline Eastern Cape & 1 & 24 & 2 & 18 \\
\hline Free State & 1 & 9 & 2 & 23 \\
\hline Gauteng & 2 & 43 & 2 & 17 \\
\hline KwaZulu Natal & 2 & 57 & 2 & 28 \\
\hline Limpopo & 1 & 16 & 2 & 20 \\
\hline Total & 7 & 132 & 10 & 106 \\
\hline
\end{tabular}

In addition to teachers, stakeholders from different organisations in South Africa and representatives from various schools who were observed to have good practice were also involved in the PRA process. Additional stakeholder-participants were selected through snowball sampling, which entails identified participants recruiting others that could be beneficial for the research (Naderifar, Goli, and Ghaljaei 2017). As a result we were able to include participants that were not known to the research team or may have been difficult to 
reach without someone introducing us to one another (Flick 2011). The PRA-based workshops explored their thoughts on the needs of learners with visual impairment and their ideas on the postgraduate qualification in visual impairment studies. To at least acquire a representative sample of stakeholder-participants, Table 2 depicts the stakeholders selected.

Table 2: Stakeholder-participants

\begin{tabular}{|c|c|c|}
\hline Institution & $\begin{array}{c}\text { Number of } \\
\text { participants }\end{array}$ & Area of Expertise \\
\hline $\begin{array}{l}\text { South African Council for the } \\
\text { Blind }\end{array}$ & 7 & $\begin{array}{l}\text { Experts in serving, supporting and facilitating the } \\
\text { prevention of blindness, rehabilitation, community } \\
\text { development, training and education of South } \\
\text { African people with visual impairment. }\end{array}$ \\
\hline Blind South Africa & 6 & Experts in training and orientation in Braille. \\
\hline $\begin{array}{l}\text { South African Library for the } \\
\text { Blind }\end{array}$ & 3 & $\begin{array}{l}\text { Braille consultant of South Africa, expertise in Braille } \\
\text { training and Braille codes. }\end{array}$ \\
\hline $\begin{array}{l}\text { South African Guide Dog } \\
\text { Association }\end{array}$ & 2 & $\begin{array}{l}\text { An association that enhances the mobility and } \\
\text { independence of people who have visual, physical } \\
\text { and/or developmental needs. }\end{array}$ \\
\hline South African Braille Authority & 1 & $\begin{array}{l}\text { A standard setting body that promotes and } \\
\text { advocates Braille and Braille-related matters in } \\
\text { South Africa. }\end{array}$ \\
\hline Private consultant & 1 & $\begin{array}{l}\text { Ten years' experience as a school principal of a } \\
\text { special school for the Blind and partially sighted. }\end{array}$ \\
\hline $\begin{array}{l}\text { School 4, School 6, School 9, } \\
\text { School } 13 \text { (special needs } \\
\text { schools) and School } 18 \text { (this } \\
\text { school was not visited but } 1 \\
\text { expert stakeholder participated) }\end{array}$ & 13 & $\begin{array}{l}\text { Teachers at special needs schools for the Blind and } \\
\text { partially sighted, with three of these teachers being } \\
\text { blind themselves. }\end{array}$ \\
\hline $\begin{array}{l}\text { University lecturers and } \\
\text { professors }\end{array}$ & 10 & $\begin{array}{l}\text { Academics who have experience in working with } \\
\text { students with visual impairment, with one lecturer } \\
\text { being visually impaired himself. }\end{array}$ \\
\hline $\begin{array}{l}\text { District level officials and } \\
\text { teachers }\end{array}$ & 7 & $\begin{array}{l}\text { Learning support advisors, psychologist and } \\
\text { teachers who have learners with visual impairment } \\
\text { in their classrooms and those working in schools for } \\
\text { the Blind and partially sighted. }\end{array}$ \\
\hline Total & 50 & \\
\hline
\end{tabular}

\section{Data generation, documentation and analysis}

Throughout our study we pursued a participatory approach and were guided by PRA principles. Teachers and stakeholders were regarded as partners in this study who participated in PRAbased workshops and presentations (James 2007). Participants from 17 schools were involved PRA-based workshops. These workshops were co-facilitated by the research team and the focus of these workshops with teachers was the experiences and needs of teachers who teach learners with visual impairment, as well as their recommendations on suitable content for inclusion in a related postgraduate qualification. Two PRA-based workshops with stakeholders in the field of visual impairment were also co-facilitated. During the first workshop, stakeholders were requested to provide input for the proposed postgraduate programme in terms of suitable content for the modules. In the second workshop, stakeholders had the opportunity to reflect on their involvement in the PRA process of programme development. 
Beyond PRA-based activities we used other data generation sources that include observation-as-context-of-interaction, which highlights the importance of a researcher being acquainted with the context in which a study is conducted, and the human interactions that occur in that context among participants (Kumar 2005). We observed the participants' teaching and interacting with learners for the duration of one morning at each of the 17 schools. In addition, all PRA sessions were observed and recorded. By utilising this technique, we could obtain data on how participants taught and which needs were displayed when working with learners with visual impairment (Kumar 2005). We also facilitated nine semi-structures interviews (James 2007) as a way to generate data in discussion with experts who hold knowledge in the field of visual impairment (Krueger and Casey 2000), more specifically with stakeholders who were not able to attend the two stakeholder colloquiums, or for follow-up discussions with specific teacher-participants to explore or clarify uncertainties identified during the PRA-based activities and discussions. During the semi-structured interviews with individual participants we aimed to gain an understanding of their experiences and needs when working with learners with visual impairment. Stakeholders outside the school context furthermore provided expert knowledge on visual impairment and the development of a suitable postgraduate qualification and its content, for practising and prospective teachers. In documenting our observations, we safely kept participants' posters which were generated during PRA-based workshops, we also utilised field notes, reflective journals and audio-visual strategies in documenting the data (James 2007).

The results reported on this article refer to participants' experiences of PRA as a methodology and their taking part in developing the qualification. However, during these workshops teachers' understanding and implication of inclusive education, needs of learners, their needs and competencies as teachers were explored. Both teachers and stakeholders were also asked about their perceptions of what can be included in the postgraduate qualification in visual impairment studies. For analysing the data, we used thematic inductive analysis, following steps indicated by Braun and Clarke (2006). This was completed subsequent to the transcribing audio recorded discussions and interviews. In attempting a rigours study, we employed credibility, authenticity, dependability, confirmability and transferability strategies (Maree 2007).

\section{ETHICAL CONSIDERATIONS}

Prior to engaging in data generation we obtained ethical clearance from the University of Pretoria and permission from education departments of the provinces we visited. We adhered to ethical guidelines stipulated by the University of Pretoria including respecting participants, 
obtaining informed concerned from participants willing to become part of the study and allowing voluntary participation (Jelsma and Clow 2005). We kept the data privately and confidentially as alluded to the participants, we also respected their right to privacy (Jelsma and Clow 2005). Participants were not coerced or bribed in any way for their participation and it was emphasised that they can withdraw at any time without explanation (Jelsma and Clow 2005). Additionally, we further adhered to the ethical considerations of no deception, trust and protection from harm; we assured participants that their identities will not be revealed unless they give us permission to do so and that our report will be as scholarly and ethical as possible (Jelsma and Clow 2005).

\section{RESULTS}

The use of PRA and thematic inductive analysis for this study has resulted in three themes with two related subthemes each. The first theme relates to participants' own perceptions of PRA, secondly participants' understanding of inclusive education and lastly participants' identifying the systemic challenges that learners with visual impairment are faced with. Under the first theme two subthemes emerged namely partnership formation and a platform for mutual learning. The second theme presented two subthemes namely inclusive education as nondiscriminatory and teacher training as a requirement for successful implementation of inclusive education with learners with visual impairment. Lastly, the third theme also has two subthemes namely lack of accommodation for learners with visual impairment and shortage of trained teachers to teach learners with visual impairment.

\section{Theme one: Participants' perceptions of PRA}

Participants perceived PRA as a process that allows them to get to know other colleagues and learn from them. They realised that through PRA it is possible to meet other like-minded people who are also on the mission to do to well with learners with visual impairment. The implementation of PRA in this particular study showed that it is possible for colleagues from various parts of the country to somehow join forces and expertise for the sake of advancing their knowledge and skills to be better equipped to teach and support learners with visual impairment. This theme represents the useful partnerships formed during the course of the study and through PRA-based activities. This theme also discusses the mutual learning that took place among participants during their interactions and presentations. 


\section{Subtheme 1: Partnership formation}

In the first subtheme within this theme it is depicted that participants in this study managed to form partnerships that have been longed for. Participants mentioned that it is necessary for them to team up even beyond this study in order to continue fighting for the rights of learners with visual impairment. The networking that led to partnership formation between the teachers of different schools and the various expert stakeholders seemingly supported interaction, lively discussions and the sharing of valuable ideas on accommodating learners with visual impairment and what this implies. By establishing working relationships and forming sustainable networks, participants were reportedly able to network with others in sector. They (participants) alluded to the element that in their experience, researchers do not necessarily contact experts; they (researchers) rather assume the details of what happens in the field. Participants in this study were appreciative of the fact that nothing was assumed, however, their knowledge and expertise were taken into account during the PRA process, it was understood that they are research partners and as a result main sources of information.

\section{Subtheme 2: Mutual learning}

In the second subtheme participants reported that PRA created a platform for them to learn from one another and share best practices. This particular subtheme has brought participants to the realisation that as they respond to some of the prompts in a group setting, they are actually teaching and disseminating knowledge and information that is beneficial to their colleagues and that they can replicate and use some information for the benefit of learners with visual impairment. During the course of this study, it became evident that participants are filled with knowledge and expertise that are necessary for the development of the qualification. It is with their willingness that they collaborated successfully during the PRA process as they came up with modules that will be beneficial to equip teachers of learners with visual impairment. Participants were observed to share their knowledge and this presented as evidence that they possessed the knowledge and could easily share and expand on it through the PRA process.

\section{Theme two: Understanding of inclusive education}

On the second theme participants depicted their understanding of inclusive education policy and its implications for them as teachers working with learners with special needs, especially learners with visual impairment. In the first instance teacher-participants understood inclusive education as not discriminating against any learner despite of the differences that may be evident. Secondly, teachers came to the realisation that the successful implementation of inclusive education policy implies them receiving training in that regard. 


\section{Subtheme 1: Inclusive education as non-discriminatory}

In the first subtheme of this theme, teacher-participants reflected on their understanding of inclusive education as a non-discriminatory act. The teacher-participants seemed aware of the fact that inclusive education policy propagates non-discrimination and respect for learners with special needs - for example visual impairment - as well as curriculum adaptation to allow for equal access to educational opportunities and resources for all learners. According to the participants, inclusive education entails the provision of equal access for all to quality education, thereby allowing all learners to have access to opportunities and resources. The participants acknowledged that in an inclusive all learners can learn although some may require more support than other, additionally all learner differences should be respected and accommodated accordingly. Furthermore, participants were of the view that within the inclusive education, learners experiencing barriers to learning need to be supported maximally and that any systemic barriers be lessened so as to promote equal access and participation of learners.

\section{Subtheme 2: Teacher training as a requirement for successful implementation of inclusive education with learners with visual impairment}

In the second subtheme, teacher-participants were able to identify areas of knowledge, skills and resources that they viewed as important to implement in inclusive education with learners with visual impairment. Teachers indicated the need for knowledge and the related skills and resources on aspects such as Braille, screening procedures and suitable teaching strategies when working with and including learners with visual impairment. One of the areas that they mentioned that they require training on is classroom management and disciplining of learners with special needs in a way that would not seem as if they are transgressing learners' rights. Additionally, teacher-participants reportedly require training on the relevant teaching and assessment techniques for learners with visual impairment so that all learners can be able to access the curriculum and be fairly assessed. Participants realised the importance of external support for the implementation of inclusive education policy, implying the need for more indepth understanding of the policy and continued training for implementation. Teachers furthermore indicated the need for training or guidance on how to facilitate referral pathways for learners with special needs as involvement of various stakeholders in support of learners is required in an inclusive setting. 


\section{Theme three: Identification of systemic challenges}

The use of PRA assisted participants in identifying various challenges that have an impact on the accommodation and progress of learners with visual impairment and need to be addressed. Through participating in PRA based workshops, participants realised that there are a number of challenges that affect not only the progress but also the learning and development of learners with visual impairment. These challenges appear within the classroom and outside. However, as participants took part in the PRA process they further realised that their other colleagues are also aware of similar, if not more, challenges. Thus, this realisation pushed participants to form alliances beyond this study in order to address those needs that they can be able to address with their capacity.

\section{Subtheme 1: Lack of accommodation for learners with visual impairment}

The first subtheme refers to the realisation that learners with visual impairment are inadequately accommodated. This feeling was brought on by the fact that special needs schools are treated similar to the mainstream schools; participants therefore viewed this as unfair and not beneficial to their learners with visual impairment. Teacher-participants mentioned that for learners with visual impairment their experience is that the curriculum is good but not adapted, question papers and text books are also not adapted to accommodate learners with visual impairment. In addition, the learning environment and teaching strategies also appeared to be problematic areas when working with learners with visual impairment. For instance, most classrooms were found to not have proper lighting and seating arrangements and some teachers who teach specific subjects such tourism seemed to find it difficult explain to learners with visual impairment for example where different destinations are located, the lack of relevant Learning and Teaching Support Material (LTSM) also worsened the situation. Participating in PRA-based workshops has brought to the attention of participants that as much as they need to differentiate the curriculum for learners with visual impairment, it should not be the same way as it is done for any other learner with a disability. Furthermore, participants shared the experience that it presents increasingly difficult to apply for support such as concessions and other necessary accommodations for learners with visual impairment. They mentioned that the process is long and that there is hardly any positive response from the responsible government department on those applications.

\section{Subtheme 2: Shortage of trained teachers to teach learners with visual impairment}

The second subtheme refers to the absence of well-trained teachers to teach and support learners 
with visual impairment. According to the participants, shortage of well-trained and equipped teachers is one of the major challenges faced in schools, especially those schools for partially sighted and blind (in addition to schools for the disabled in general). Scarcity of these teachers reflects back on the learners' learning and progress as at times during tuition time teachers need to go for training and workshops that will enhance their skills to work with learners with visual impairment. Besides teachers not being sufficient, there is also an issue of officials that are required to monitor the implementation progress and support and provide further training to teachers, these officials were reportedly also lacking training. In this regard, teacherparticipants shared the view that departmental officials who are responsible for training them seemingly possessed limited understanding of the skills required by teachers to be able to do this. Therefore, developing a postgraduate qualification in the field of visual impairment was viewed as will be assisting to address such challenges.

\section{DISCUSSION}

The study reported on in this article intended to develop a postgraduate qualification by implementing the process of PRA through engaging with teachers and relevant stakeholders in the field of visual impairment. Although the traditional methods of data generation were employed, PRA seemed valuable for this particular study. PRA is known for its ability to create partnerships that are sustainable for the development of participants' communities (Kerkale and Pittila 2006). As hoped for, PRA brought together researchers, teacher-participants and stakeholders in the field of visual impairment to develop a postgraduate qualification. As indicated, PRA is known to enhance the establishment of research partnerships with participants as well as continued collaboration (Chambers 2008). This study was characterised by collaboration among researchers, teachers and expert stakeholders in the field of visual impairment with the joint goal of conceptualising and identifying possible learning content for a postgraduate qualification in this area. Due to the fact that this study was collaborative in nature, the research team learnt from the participants, and they (participants) learnt from one another. This confirms that partnerships that were formed benefited all involved, thereby supporting the work of Chambers (2012) who views relationships and partnerships in PRA as vital to achieve a common goal.

Throughout, participants shared their experiences and ideas during PRA activities as well as in informal conversations. Thus we found that the sharing of ideas and mutual learning is not restricted to formal discussions or data generation activities but can occur in any context, particularly when rapport has been established between the participants themselves and between them and research team members. Such a culture of sharing typically encourages 
participants to fulfil the expected role of being co-constructers of knowledge, which is what took place in this study when teachers and stakeholders in collaboration with the research team co-constructed ideas for the proposed qualification. It was also found that the interaction between teachers improved at some of the schools, as a result of their participation in this study, which proves that when discussions and methods are dynamic, the likelihood of participants being dedicated to contribute is strong (Lunch and Lunch 2006). Improved interaction was furthermore evident between some teachers and learners with visual impairment, as teachers learnt from their fellow participants during discussions, and saw it fit to start applying newly gained knowledge and skills, in turn supporting their interaction with learners.

During the implementation of PRA it became evident that the said qualification is much needed by special needs and full service school teachers as well as other professionals working and interacting with children with visual impairment. Through the implementation of this methodology, PRA, findings demonstrate that collaboration is possible throughout various professionals and that it is possible to rely on each other's strengths and knowledge for the advancement of teacher education. Furthermore, findings demonstrate the significance of gathering information from the people who have first-hand experience of how it feels to work, interact, teach and support learners and/or children with visual impairment without adequate training and knowledge. However, participants as a result took ownership of the research process and were committed to making a contribution as they noticed that learning was reciprocated. In addition, they applied their newly gained knowledge and skills in their working environments in support of their teaching practice. Thus, this finding provides emphasise to the importance of collaborative partnerships between education researchers and teachers so that teachers are able to take ownership of such a process of change, form knowledge networks and improve on their practice (Ebersöhn, Ferreira, and Beukes 2012). As such, the participants did not only commit to contributing to the development of a qualification but also to support learners with visual impairment more effectively at the schools where they were employed.

Participants realised the importance of training and ongoing support with regard to the implementation of inclusive education in the context of visual impairment. As such, participation in PRA-based activities facilitated participants' awareness of their own competence and that they possessed the answer to many problems and could make valuable contributions, yet also enhanced their awareness of areas where they could gain more knowledge and skills. Through participation, participants became aware and cognisant of their own shortcomings and eventually result in their seeking assistance to gain further knowledge and skills. As a result, as people become aware of what lies within them, they will bring that to life and use it for their advantage while focusing on the ongoing process of learning and 
discovering new things (Freire 1972).

In this regard, it found that the participants indicated the need to be better informed and understand inclusive education policy and its proposed implementation. They specifically referred to the importance of ongoing training and support in this area. This finding is confirmed by the fact that several legislative guidelines need to be in place, understood and implemented by teachers on ground level for inclusive education to provide maximum support to learners with special needs (Department of Education 2007). As such, this study provides supportive evidence that participation in a PRA process can result in participants focusing and valuing the development of their own knowledge and skills base, and realising the importance of training, if needed, to reach their goal.

Regardless of the challenges that PRA has that have the potential to withhold its use within certain context, PRA as a methodology in this study proved that it can be applied in different contexts for different research studies. Throughout this process, participants supported each other by means of sharing good practices, sharing gloomy moments and also exchanging contact details for further support beyond this study. The connection that arose among the participants further demonstrated that the partnership initiated has been long overdue. Against this background, teachers and stakeholders in our study valued the teamwork and can thus be viewed as social representatives who came together to instil a much needed change into the lives of current and prospective teachers in the field of visual impairment (Van Dijk 2006).

In conclusion, participants collaborated with researchers in reaching the joint goal of conceptualising and identifying suitable content for the proposed qualification through the PRA process. Participants displayed commitment and were enthusiastic to contribute, due to their seemingly realising the importance and potential value of the qualification, appreciating that they were being heard, and experiencing themselves as partners that were valued for their knowledge and expertise in the specialised field of enquiry.

\section{ACKNOWLEDGEMENTS}

Research funding: European Union (EU) and Department of Higher Education and Training (DHET).

\section{REFERENCES}

Augestad, L. B. 2017. "Self-concept and self-esteem among children and young adults with visual impairment: A systematic review." Cogent Psychology 4: 1-12. https://doi.org/10.1080/ 23311908.2017.1319652 (Accessed 14 September 2019).

American Foundation for the Blind. 2011. "Visual impairment and Blindness." http://afb.org (Accessed 20 January 2018). 
Andreou, Y. and S. McCall. 2010. "Using the voice of the child who is blind as a tool for exploring spatial perception." The British Journal of Visual Impairment 28(2): 113-129.

Bailey, G. 2009. What can you see - supporting the social development of young people who are blind or partially sighted. RNIB

Bayram, G. I., S. M. Corlu, E. Aydın, D. Ortaçtepe, and B. Alapala. 2015. "An exploratory study of visually impaired students' perceptions of inclusive mathematics education." British Journal of Visual Impairment 33(3): 212-219.

Berry, R. A. W. 2008. "Novice teachers' conceptions of fairness in inclusion classrooms." Teaching and Teacher Education 24: 1149-1159.

Bradley-Johnson, S. and S. Morgan. 2002. "Best practices in planning effective instruction for students who are visually impaired or blind." In Best practices in school psychology IV, ed. A. Thomas and J. Grimes. Bethesda, MD: National Association of School Psychologists.

Braun, V. and V. Clarke. 2006. "Using Thematic Analysis in Psychology." Qualitative Research in Psychology 3(2): 77-101.

Brown, J. E. and W. Beamish. 2012. "The Changing Role and Practice of Teachers of Students with Visual Impairments: Practitioners' Views from Australia." Journal of Visual Impairment \& Blindness 106(2): 81-92.

Brydges, C. and P. Mkandawire. 2016. "Perceptions and concerns about inclusive education among students with visual impairments in Lagos, Nigeria." International Journal of Disability, Development and Education 64(2): 211-225. http://dx.doi.org/10.1080/1034912X.2016.1183768 (Accessed 15 September 2017).

Busemeyer, M. and J. Vossiek. 2015. "Reforming Education Governance Through Local Capacitybuilding: A Case Study of the "Learning Locally' Programme in Germany." OECD Education Working Papers, 113. OECD Publishing.

Carcary, M. 2009. "The Research Audit Trial: Enhancing Trustworthiness in Qualitative Inquiry." Electronic Journal of Business Research Methods 7(1): 11-24. www.ejbrm.com (Accessed 15 June 2017).

Carney, S., C. Engbretson, K. Scammell, and V. Sheppard. 2003. Teaching Students with Visual Impairments: A Guide for the Support Team. http://www.sasked.gov.sk.ca/k/pecs/se/ publications.html (Accessed 15 June 2017).

Chambers, R. 1994. "Participatory Rural Appraisal (PRA): Analysis of experience." World Development 22(9): 1253-1268.

Chambers, R. 2008. "PRA, PLA and pluralism: Practice and theory." In The Sage handbook of action research. Participative inquiry and practice, ed. Peter Reason and Hilary Bradbury. $2^{\text {nd }}$ Edition. London: Sage.

Chambers, R. 2012. Revolutions in Development Inquiry. London: Imprint Routledge.

Cheatham-Rojas, A. and E. Shen. 2008. "CBPR with Cambodian girls in Long Beach, California: A case study." In Community-Based Participatory Research for Health: From process to outcomes, ed. M. Minkler and N. Wallerstein. United States of America: Jossey-Bass.

Chilisa, B. 2012. Indigenous research methodologies. Thousand Oaks: Sage.

Datta, P. and J. Talukdar. 2016. "The impact of vision impairment on students' self-concept." International Journal of Inclusive Education 20(6): 659-672.

Department of Basic Education. 2001. White paper 6: Special Needs Education Building an inclusive education and training system. Pretoria: Department of Education.

Department of Basic Education. 2010. Guidelines for Full-service/Inclusive Schools. Pretoria: South Africa.

Department of Basic Education. 2015a. Report on the implementation of education white paper 6 on inclusive education: An overview period 2013-2015. Pretoria: South Africa.

Department of Basic Education. 2015b. Media release responding to Human Rights Watch's report. 
Pretoria: Department of Education.

Department of Basic Education. 2016. Report on progress in the schooling sector against key learner performance and attainment indicators. Pretoria: Department of Education.

Department of Basic Education and MIET Africa. 2010. National Support Pack. Durban: MIET Africa.

Department of Education. 2005a. Conceptual and Operational Guidelines for the Implementation of Inclusive Education: Special schools as Resource Centres. Education White Paper 6: Special Needs Education. Pretoria: South Africa.

Department of Education. 2005b. Guidelines for Inclusive Learning Programmes. Education White Paper 6: Special Needs Education. Pretoria: South Africa.

Department of Education. 2007. Guidelines to Ensure Quality Education and Support in Special Schools and Special School Resource Centres. Pretoria: South Africa

Ebersöhn, L., R. Ferreira, and J. Beukes. 2012. "An attractive choice: Education researchers' use of participatory methodology." South African Journal of Higher Education 26(3): 455-471.

Fals-Borda, O. 1991. "Remarking knowledge." In Action and knowledge: Breaking the monopoly with participatory action-research, ed. O. Fals-Borda and M. Rahman. New York: Apex press.

Fazzi, E., J. Galli, and S. Micheletti. 2012. "Visual impairment: A common sequelae of preterm birth." Neoreviews 13(9): 542-550.

Ferguson, G. 2014. "Including children with disabilities in mainstream education: An exploration of the challenges and considerations for parents and primary school teachers." Unpublished Masters dissertation: Dublin Institute of Technology.

Fitts, W. H. and W. L. Warren. 2003. Tennessee Self-concept Scale Manual. $2^{\text {nd }}$ Edition. Los Angeles, CA: Western Psychological Services

Flick, U. 2011. Designing qualitative research. London: SAGE Publications Ltd.

Freire, P. 1972. Pedagogy of the oppressed. Harmondsworth: Penguin.

George, A. L. and C. Duquette. 2006. "The Psychosocial Experiences of a Student with Low Vision." JVIB 100(3): 1-22.

Gerring, J. 2004. "What Is a Case Study and What Is It Good for?" The American Political Science Review 98(2): 341-354.

Gibson, M. 2002. "Doing a doctorate using a participatory action research framework in the context of community health." Qualitative Health Research 12(4): 546-588.

Given, L. M. (Ed.). 2008. The Sage Encyclopedia of Qualitative Research Methods, 697-698. $2^{\text {nd }}$ Edition. Thousand Oaks CA: SAGE.

Grenier, L. 1998. Working with indigenous knowledge: A guide for researchers. Ottawa: International development research centre.

Habulezi, J. and T. N. Phasha. 2012. "Provision of learning support to learners with visual impairment in Botswana: A case study." Procedia-Social and Behavioral Sciences 69: 1555-1561.

Jelsma, J. and S. Clow. 2005. "Ethical issues relating to qualitative research." SA Journal of Physiotherapy 61(1): 3-6

James, E. A. 2007. "Qualitative Data Collection: Participatory Action Research for Educational Leadership." Educational Action Research 14(4): 525-533.

Janse van Rensburg, J. P. L. 2005. "Overview of qualifications: Road construction, materials testing, civil engineering and construction management qualifications registered on the national qualifications framework." Document transformation technologies: Proceedings of the $24^{\text {th }}$ Southern African Transport Conference.

Johnson-Jones, K. J. 2017. "Educating students with visual impairments in the general education setting." Unpublished Doctoral thesis: University of Southern Mississippi.

Kamal, L. 2017. "Teaching students with visual impairments in an inclusive educational setting: a case 
from Nepal." International Journal of Inclusive Education 21(1): 1-13. http://dx.doi.org/10.1080/ 13603116.2016.1184323 (Accessed 12 December 2017).

Khalim, Z., M. S. Norshidah, and M. J. Zalizan. 2011. "Assessment of Social Skills Among Visually Impaired Students." The International Journal of Learning 17(12): 89-97.

Kapoor, D. and S. Jordan. 2009. Education, participatory action research and education: International perspectives. Palgrave MacMillan: United States of America.

Kapur, R. 2018. "Challenges experienced by visually impaired students in education." https://www.researchgate.net/publication/323833804_Challenges_Experienced_by_Visually_Im paired_Students_in_Education (Accessed 14 September 2019).

Kass, A. 2012. "Anger Management: Guide for Teens." www.GoSmartLife.com. (Accessed 12 February 2019).

Kerkale, J. and I. Pittila. 2006. "Participatory action research as a method for developing leadership and quality." International Journal of Leadership in Education 9(3): 251-268.

Krueger, R. A. and M. A. Casey. 2000. Focus groups: A practical guide for applied research. $3^{\text {rd }}$ Edition. Thousand Oaks, CA: Sage.

Kumar, R. 2005. Research Methodology: A step-by-step guide for beginners. London: SAGE publishers.

Kumar, S. and J. Signh. 2013. "Emotional intelligence and adjustment among visually impaired and sighted school students." Asian Journal of Multi-dimensional Research 2(8): 1-8.

KZNDoE and MIET see KwaZulu Natal Department of Education and MIET Africa.

KwaZulu Natal Department of Education and MIET Africa. 2010. Special schools as resource centres: Briefing document. KZN

Lamichhane, K. 2017. "Teaching students with visual impairments in an inclusive educational setting: a case from Nepal." International Journal of Inclusive Education 21(1): 1-13.

Lane, J. D., H. M. Wellman, S. L. Olson, J. LaBounty, and D. C. R. Kerr. 2010. "Theory of mind and emotion understanding predict moral development in early childhood." British Journal of Developmental Psychology, 28(4), 871-889.

Landsberg, E., D. Kruger, and N. Nel. (Eds.). 2015. Addressing Barriers to Learning: A South African Perspective. Pretoria: Van Schaik Publishers.

Lunch, N. and C. Lunch. 2006. Insights into participatory video: A handbook for the field. Sevierville, TN: Insight Publishing.

Maree, J. G. (Ed.). 2007. First steps in research. Pretoria: Van Shaik Publishers.

Masango, J. M. 2013. "The roles of the principal and the SBST in supporting teachers teaching inclusive education." Unpublished Masters dissertation: University of Pretoria.

Mastropieri, M. A. and T. E. Scruggs. 2010. The Inclusive Classroom: Strategies for Effective differentiated Instruction. New Jersey: Upper Saddle River.

Ministry of Education. 2006. Students with visual impairments: A learning resource for teachers. British Columbia: Ministry of education.

Mosca, R. 2015. "Language and communication development in preschool children with visual impairment: A systematic review." Unpublished dissertation: University of Pretoria.

Naderifar, M., H. Goli, and F. Ghaljaei. 2017. Snowball Sampling: A Purposeful Method of Sampling in Qualitative Research. Strides in Development of Medical Education, 14(3), 1-6.

Negash, K.H. 2017. "The inclusion of visually-impaired learners in Ethiopian secondary schools." Unpublished Doctoral dissertation. University of South Africa.

NICHCY Disability Fact Sheet \#13 2012. Visual impairments, including blindness. Retrieved on 20 January 2018 from http://nichcy.org.

Niyisabwa, O. 2016. "Strategies for enhancing access and retention of learners with visual impairments in universal primary education schools in South Western Uganda region." Unpublished Doctoral 
Thesis. Department of Special Needs Education: Kenyatta University.

Penda, A., D. Ndhlovu, and S. Kasonde-Ng'andu. 2015. "The challenges in teaching learners with visual impairment in Zambia." International Journal of Multidisciplinary Research and Development 2(4): $157-166$.

Roe, J. 2008. "Social inclusion: Meeting the social-emotional needs of children with vision needs." The British Journal of Visual Impairment 26(2): 147-158.

Sacks, S. Z. and K. E. Wolffe. 2006. Teaching social skills to students with visual impairment: From theory to practice. New York: AFB Press, American Foundation for the Blind.

Sacks, S. Z and R. K. Silberman. 2000. "Social skills." In Foundation of education: Instructional strategies for teaching children and youth with visual impairment, ed. A. J. Keoeing and M. C. Holbrook, 616 - 652. New York: AFB Press, American Foundation for the Blind.

Schinazi, V. R. 2007. Psychosocial implications of blindness and low-vision. Centre for Advanced Spatial Analysis: University College London, Royal London Society for the Blind (RLSB).

Silberman, R. K., S. Bruce, and C. Nelson. 2004. "Children with sensory impairments.” In Educating children with multiple disabilities, ed. F. P. Orelove, D. Sobsey, and R. K. Silberman. Baltimore, MD: Brooks Publishing.

SAQA see South African Qualifications Authority.

South African Qualifications Authority. 2013. Policy and Criteria for the Registration of Qualifications and Part Qualifications on the National Qualifications Framework. Pretoria: Waterkloof.

Tadić, V., L. Pring, and N. Dale. 2010. "Are language and social communication intact in children with congenital visual impairment at school age?" Journal of Child Psychology and Psychiatry 51(6): 696-705.

Terzi, L. 2005. "Beyond the dilemma of difference: The capability approach to disability and special educational needs." Journal of Philosophy of Education 39(3): 443-459.

Tolman, J., R. D. Hill, J. J. Kleinschmidt, and C. H. Gregg. 2005. "Psychosocial Adaptation to Visual Impairment and Its Relationship to Depressive Affect in Older Adults with Age-Related Macular Degeneration." The Gerontological Society of America 45(6): 747-753.

Ueda, Y. 2018. "Psychosocial adaptation to visual impairment". In Causes and Coping with Visual Impairment and Blindness, ed. S. Rumelt, 93-108. IntechOpen: Rijeka. https://oi.org/ 10.5772/intechopen.70269 (Accessed 14 September 2019).

UNESCO. 2001. Understanding and responding to children's needs in inclusive classrooms. Paris.

UNESCO. 2004. Embracing Diversity: Toolkit for creating inclusive, learning-friendly environments. Thailand.

Van Dijk, J. 2006. The network society. London: SAGE Publications.

Verdier, K. 2016. "Inclusion in and out of the classroom: A longitudinal study of students with visual impairments in inclusive education." British Journal of Visual Impairment 34(2): 132-142.

Waterfield, J. and B. West. 2008. Meeting the specific requirements of Blind and Partially Sighted Students studying in Higher Education in the UK. University of Plymouth: Plymouth.

Willings, C. 2017. Teaching students with visual impairment: Impact on development and learning. https://www.teachingvisuallyimpaired.com/impact-on-development--learning.html (Accessed 14 September 2019). 